\title{
Imágenes de la epidemia de fiebres tercianas en la Topografía hipocrática... (1795) de Félix Ibáñez
}

\author{
Images of the epidemic of tertian fevers in \\ Topografía hipocrática... (1795) by Félix Ibáñez
}

\author{
Katarzyna Płaczek-Kaszyńska \\ Instytut Filologii Romańskiej \\ Uniwersytet im. Adama Mickiewicza w Poznaniu \\ katarzyna.placzek@amu.edu.pl
}

\begin{abstract}
The aim of the study is to analyse the images of the epidemic of tertian fevers in Topografia hipocrática o descripción de la epidemia de calenturas tercianas intermitentes malignas, continuo-remitentes, perniciosas complicadas (1795) by Félix Ibáñez (ca. 1738-1808), one of the most comprehensive studies dedicated to malaria in the $18^{\text {th }}$ century Spain. They are examined from the perspective of the importance of visual representations of the illness in the $18^{\text {th }}$ century, related to a radical transition from a logocentric to a visually dependent culture, which took place in the field of art and medicine in the Enlightenment.
\end{abstract}

Keywords: $18^{\text {th }}$ century, Félix Ibáñez, malaria, medical discourse, tertian fever, visual representation

En el siglo XVIII España fue acometida por una serie de epidemias y brotes endémicos con diversos grados de mortalidad ${ }^{1}$. Aunque casi no se registraron casos de peste (cf. Granjel, 1979, p. 105), la enfermedad más grave de los siglos anteriores, la presencia de la viruela y del tabardillo (el tifus exantemático), así como la aparición de una nueva enfermedad -la fiebre amarilla-, ocasionaron la muerte de muchos españoles. A finales de siglo la causa de una de las epidemias más graves en

${ }^{1}$ El presente trabajo se ha realizado en el marco del proyecto "Formas de vida, formas de literatura" (2bH 150237 83, Programa Nacional del Desarrollo de las Ciencias Humanas) financiado por el Ministerio de Ciencia y Educación Superior polaco. 
varias regiones de España fue la fiebre terciana, es decir, una calentura intermitente que se producía cada tres días: la malaria. Según observa Carmona (2005, p. 126), el morbo palúdico "se constituyó en el marco de la Europa meridional como un mal endémico, es decir, habitual o fijo según las estaciones, causante [...] de un alza notable de la mortalidad extraordinaria de carácter epidémico" ${ }^{2}$. La asiduidad y la gravedad de las epidemias de tercianas a finales del setecientos dieron lugar a una amplia producción de textos médicos dedicados al tema de esta enfermedad. Entre estos escritos se encuentra Topografia hipocrática o descripción de la epidemia de calenturas tercianas intermitentes malignas, continuo-remitentes, perniciosas complicadas (1795) de Félix Ibáñez (ca. 1738-1808), uno de los compendios más exhaustivos sobre el paludismo publicados en el siglo XVIII en España ${ }^{3}$. El objetivo del presente artículo es analizar las imágenes que el autor del tratado utiliza para representar la epidemia de fiebres tercianas. El análisis se llevará a cabo desde la perspectiva de la importancia de lo visual en el arte y la medicina del siglo XVIII.

La obra de Félix Ibáñez surgió a raíz de una grave epidemia de fiebres tercianas que ocurrió en La Alcarria en los años 1783-1791. Presenta diferentes hipótesis acerca de las causas de la enfermedad, así como los métodos curativos aplicados tanto en el siglo XVIII como en los tiempos anteriores. Es más, como observa Alegre Carvajal (2019, p. 254), Ibáñez "mostraba una alta erudición en cuanto a las modernas teorías sobre epidemiología". En efecto, el tratado abunda en referencias a las observaciones de otros médicos, desde Hipócrates, Avicena y Galeno hasta los profesionales contemporáneos al autor: Boerhaave, Masdevall, y Ased y Latorre. Paralelamente, el trabajo de Ibáñez pone de manifiesto no solo sus vastos conocimientos teóricos, sino también amplios saberes derivados de su práctica clínica: siendo médico titular de Pastrana desde 1780 hasta 1808 (cf. Alegre Carvajal, 2019, p. 254-255), adquirió una considerable experiencia en el tratamiento de muchas enfermedades, entre ellas, la fiebre terciana ${ }^{4}$. En su tratado encontramos cuantiosos estudios de casos médicos que trató a lo largo de su práctica en La Alcarria.

Antes de que pasemos al análisis de la representación de la epidemia en la Topografia hipocrática..., es necesario detenerse en el comentario de su título,

\footnotetext{
${ }^{2}$ Vicente Pérez-Moreda (cit. en Giménez-Font, 2008, p. 145) estima que entre los años 1783 y 1786 en España hubo más de 1000000 de enfermos, unos 100.000 de los cuales murieron.

${ }^{3}$ Entre los escritos médicos del siglo XVIII que tratan de las calenturas intermitentes pueden mencionarse Rayos de luz práctica... de las fiebres intermitentes (1731) de Félix Pacheco, De las fiebres intermitentes, sus causas y modo de hacerse (1734) de Luis Enríquez, Tratado de las calenturas, según la observación del mecanicismo (1751) de Andrés Piquer y Arrufat, Relación de las Epidemias de calenturas pútridas y malignas (1786) de José Masdevall, Historia de la epidemia acaecida en la ciudad de Barbastro en el año 1784 (1786) de Antonio de Ased y Latorre, Relación de epidemias que han afligido a la ciudad de Cartagena, sus causas y método curativo (1787) de Martín Rodón y Bell y Discurso... sobre la epidemia de Pamplona (1789) de Manuel Joaquín Ortiz, entre otros.

${ }^{4}$ Alegre Carvajal (2019, p. 258) estima que durante su carrera médica Ibáñez pudo tratar a unos 4000 enfermos.
} 
estrictamente relacionado con la manera en la que el autor entiende las causas de la enfermedad. El título pone de manifiesto el parentesco del tratado con las así llamadas topografías médicas, a saber:

estudios de lugares geográficos concretos y de sus poblaciones, que se abordan desde una perspectiva higiénico-sanitaria y que comprenden, por regla general, la descripción física del punto -situación, clima, suelo, hidrografía- y la del entorno biológico -flora y fauna-; los antecedentes históricos, el temperamento físico y el carácter moral de sus habitantes, las costumbres, las condiciones de vida, los movimientos demográficos, las patologías dominantes y la distribución de las enfermedades (Casco Solís, 2001, p. 213-214).

En efecto, la obra incluye amplios pasajes dedicados a la descripción de la topografía de La Alcarria y los fenómenos meteorológicos que tuvieron allí lugar a finales del siglo XVIII. La importancia que el autor otorga a las características de la región se relaciona con las hipótesis concernientes a las causas de las fiebres tercianas: de acuerdo con las bases de la teoría miasmática, originada en el pensamiento de Hipócrates, los brotes del paludismo se asociaban con la abundancia de aguas estancadas acumuladas a consecuencia de largas e intensas precipitaciones, que daban lugar a "la formación de vapores mefíticos o miasmas ${ }^{5}$ nocivos para la salud" (Giménez-Font, 2008, p. 142). Dicho de otra forma, la malaria se vinculaba con la putrefacción del agua, que -según los médicos setecentistas- producía un aire pestilente ${ }^{6}$.

Pero la influencia de la medicina hipocrática en el tratado de Ibáñez va más allá del apego a la teoría miasmática. La primera parte del libro está dedicada exclusivamente al comentario de algunos aforismos de Hipócrates concernientes al origen de las enfermedades, en particular, de las fiebres tercianas. La segunda, considerablemente más amplia, constituye un estudio pormenorizado de las causas, tipos, síntomas y métodos curativos de esta enfermedad, enriquecido con descripciones de numerosos casos clínicos. Todos estos elementos están enmarcados en la narración de los sucesos de la epidemia que tuvo lugar en España -sobre todo, en La Alcarriaentre los años 1783-1791. En su tratado, Ibáñez se presenta como un historiador que relaciona el avance de la epidemia, otorgándole el protagonismo. Al principio de la sección dedicada al origen del brote de las tercianas, advierte:

se introdujo en el Reino la epidemia de tercianas, con tan alevosa maña, que de presto cundió por todas sus provincias, ciudades, villas y lugares. Se metió dentro de nuestras mismas casas y habitaciones, y se ha hecho enemigo doméstico [...] (p. 5)

\footnotetext{
${ }^{5}$ La cursiva es del autor del fragmento citado.

${ }^{6}$ Los dos términos que se utilizan en la lengua española para designar la enfermedad se relacionan con la teoría miasmática: el "paludismo" viene de la palabra latina palus, que significa "laguna", "pantano" (Malaria, 2014); el término "malaria" fue acuñado en Italia y surgió por la unión de las voces mala y aria, es decir, "mal aire" (Paludismo, 2014).

7 A partir de aquí, en las citas del tratado de Ibáñez, indico el número de la página correspondiente a la edición que aparece en la lista bibliográfica (Ibáñez, 1795).
} 
A lo largo de la obra, el autor constantemente recurre a la personificación de la epidemia, que se presenta como un enemigo cruel, violento y alevoso. Asimismo, pone de manifiesto la falta de métodos efectivos para prevenirla, la gran mortalidad entre los enfermos y la rapidez con la que las calenturas se difundían por la España de su tiempo. La enfermedad es un adversario traidor porque, como advierte Ibáñez, sus síntomas resultan a veces confusos y dan lugar a diagnósticos erróneos. En uno de los apartados dedicados a los tipos de las fiebres tercianas, comenta:

Las tercianas se han disfrazado aún en el modo de acometer, continuar y terminar al principio de sus accesiones o combates, se han manifestado con semblante benigno; en sus acrecentamientos han descubierto malignidad, y en la declinación han tomado partido de volver con más fuerza y vehemencia a la segunda accesión (p. 32).

En estas circunstancias, la lucha contra la enfermedad se presenta como un combate desigual, en el que la fiebre engaña a los médicos por medio de artimañas peligrosas, "disfrazándose" de nimia dolencia, es decir, ocultando su malignidad. La imagen del disfraz, elemento importante en la representación de la alevosía de la enfermedad, reaparece en otro fragmento que Ibáñez dedica al comentario de la incapacidad de los médicos para reconocer los síntomas de la fiebre terciana. Describe la confusión que producen algunos indicios de la enfermedad, y afirma:

De esta forma se han disfrazado las tercianas malignas complicadas, bajo de un pretexto oculto: y luego se han explicado con innumerables síntomas. [...] El haber visto en nuestra práctica, la solapa de las tercianas malignas, y las malas consecuencias, que se han seguido, nos ha hecho conocer, que aunque se manifestaban con piel de inocente cordero, eran en efecto, lobos nocentes que devoraban a los infelices tercianarios, y les hacían pasar de esta vida a la otra (p. 42).

El autor presenta la calentura como un lobo disfrazado de cordero y acentúa el contraste entre los dos sustantivos, emparejándolos con epítetos con significados opuestos ("inocente" versus "nocente"). El lobo -la representación de la fiebre"devora" a los enfermos: los síntomas de la calentura "abaten las fuerzas vitales" (p. 39), causando "notable desapacibilidad, pesadez, debilidad, o decaimiento de ánimo, palidez de rostro" (p. 40), hasta quitar la vida ${ }^{8}$.

Debido a estas características, la enfermedad se propagaba con rapidez, y el gran incremento del número de enfermos impuso la necesidad de buscar remedios para erradicarla o, como dice el autor, para "huir del enemigo" (p. 6). Y continúa: "aunque sea a coste y a costa de nuestra salud y vida, [los médicos] hemos de competir y veamos por quién queda la victoria" (p. 6). En su tratado, muchas veces recurre al

${ }^{8}$ La imagen de un lobo disfrazado de cordero aparece también en un pasaje de la Biblia: "Guardaos de los falsos profetas, que vienen a vosotros con disfraces de ovejas, pero por dentro son lobos rapaces" (Mateo 7:15; texto según la Biblia de Jerusalén, 1975, p. 1397), en el que el lobo -al igual que en el tratado de Ibáñez- representa el engaño y la falsedad. 
vocabulario bélico: en uno de los fragmentos citados anteriormente, habla de los "combates" (p. 32) de las tercianas, mientras que el avance de la epidemia lo presenta como una "conquista" (p. 6), "cerco" (p. 8) e "invasión" (p. 50), entre otros. A la hora de referirse al número de enfermos que sufren recidivas de la enfermedad, relata:

quedaron más desconsolados los tercianarios alistados bajo de la tirana condición de unas tercianas que concertada paz, y admitidas treguas con los mismos enfermos se hacían reversivas, y de tal manera asaltaba de nuevo, que quedaban muchos de ellos sepultados entre el innumerable tropel de cadáveres [...] (p. 6).

Al presentar las reiteraciones inesperadas de la fiebre como un asalto que supone una violación de la tregua establecida entre la malaria y los enfermos "alistados" como tercianarios -los cuales, acto seguido, pasan a formar un "tropel de cadáveres"-, el autor remite de nuevo al imaginario de la guerra. En otro pasaje en el que una vez más destaca el carácter alevoso de las recaídas que sufren los enfermos, observa, en un tono parecido, que las "tercianas muchas veces se han presentado con síntomas de paz, y bajo de un semblante pacífico, han prometido una cosa, y han ejecutado otra" (p. 32).

La asociación del tratamiento de la fiebre terciana con la imagen de la guerra puede, por tanto, relacionarse con las particularidades del desarrollo de la enfermedad: una aparición inesperada, un avance brusco y un advenimiento irregular de síntomas con diverso grado de gravedad. El uso de este recurso en las narraciones sobre la epidemia demuestra un esfuerzo por crear representaciones visuales que den imagen a lo conceptual, esto es, a lo que no tiene imagen. El interés por la "visualización" de la enfermedad en la obra de Ibáñez puede inscribirse en un contexto más amplio, el de un "giro visual", que, según Stafford (1997, p. XVIII), se produce en el universo de la medicina y del arte del siglo XVIII, y supone el paso de una cultura logocéntrica a una que se sustenta en la fuerza de la imagen. En este contexto cabe evocar una observación de Mitchell, según la cual la modernidad y los tiempos contemporáneos están marcados por una serie de giros "hacia la imagen o hacia lo visual $[\ldots]$, asociados comúnmente a la aparición de nuevas técnicas de reproducción o a la nueva interpretación de un conjunto de imágenes dentro de movimientos sociales, políticos o estéticos" (cit. en García Varas, 2017, p. 29). Entre los acontecimientos que influyeron en la progresiva "visualización" de la cultura europea, el investigador menciona, entre otros, la introducción de la perspectiva en la pintura y, más tarde, la invención de la fotografía (cf. Mitchell, 2009, p. 320). Considerada desde esta perspectiva, la creciente presencia de lo visual en la cultura dieciochesca puede relacionarse con la evolución tecnológica de la imprenta, que permitió una producción más barata $\mathrm{y}$, asimismo, una mayor difusión de las publicaciones que incluían dibujos u otro tipo de ilustraciones. A los factores que contribuyeron al aumento de la presencia de las imágenes en el setecientos se suman 
también el desarrollo y la popularización de las técnicas de reproducción gráfica tales como el aguafuerte y el aguatinta. Como observa Cera Brea (2013, p. 37), el "grabado constituyó una herramienta fundamental para la transmisión de imágenes y conocimiento antes de la invención y difusión de la fotografía". Vega (2011, p. 229), por su parte, advierte que en el periodo ilustrado "se estableció un mercado internacional de estampas y las imágenes de mayor éxito fueron las vistas de ciudades y monumentos". La investigadora asocia la gran demanda de las imágenes arquitectónicas con la popularidad de la cámara oscura que

en el siglo XVIII [...] se convirtió en un instrumento de uso y entretenimiento en buena parte de los domicilios urbanos de las principales ciudades españolas; su uso trascendió la práctica artística y educó, directa o indirectamente, a la mayor parte de la población (Vega, 2011, p. 231).

El desarrollo de la imprenta, la evolución de las técnicas de reproducción gráfica y la divulgación de la cámara oscura enriquecieron las posibilidades de conseguir representaciones visuales de lo que, hasta aquel momento, había estado fuera del alcance de la vista de una gran parte de la sociedad. Por lo tanto, el lenguaje, que había constituido la herramienta principal del acercamiento a esta esfera, empezó a ceder su posición ante la creciente presencia de la imagen.

En el ámbito de la medicina, el giro visual puede relacionarse con el desarrollo de la óptica y de instrumentos tales como el microscopio ${ }^{9}$, que fortalecieron el papel de la imagen en esta disciplina. Además, como advierte Ortega (2010, p. 168), en el siglo XVIII el médico mostraba un "deseo [...] de diferenciarse claramente del cirujano, cuyo dominio era la superficie del cuerpo y sus herramientas eran los dedos, y no la mente", ya que "se consideraba un pensador y no alguien dotado de las habilidades táctiles". Asimismo, la necesidad de distinguir la medicina del ámbito de la cirugía en el siglo XVIII, vinculada con la creciente dignificación de la primera, que se consideraba como una rama de la ciencia filosófica, supuso un intento de elevar la primacía de lo visual respecto a lo táctil. En su comentario de este fenómeno Ortega dice entonces que "[a] la mayor dignidad de la medicina frente a la cirugía, de la cabeza frente a la mano, corresponde la nobleza filosófica de la visión frente al tacto" (Ortega, 2010, p. 168).

Kennedy (2010, p. 33-36), por su parte, observa que, aunque el discurso de los médicos setecentistas se caracteriza por una sencillez y concisión que se deben al rechazo de la refinación retórica (considerada superflua), los autores de los tratados

\footnotetext{
${ }^{9}$ Respecto a esta cuestión, Ortega observa que el desarrollo de los métodos diagnósticos, debido a la invención de nuevas herramientas médicas (el oftalmoscopio, el laringoscopio, entre otros) en el siglo XIX, y la aplicación de nuevas tecnologías en los siglos posteriores (por ejemplo, el uso de los rayos $\mathrm{X}$ ) hicieron que la vista se convirtiera en "una amenaza al uso diagnóstico de los otros sentidos, especialmente la audición y el tacto" (2010, p. 169).
} 
médicos del siglo XVIII tienden a representar la enfermedad como un espectáculo, en el que los lectores -junto al autor- se convierten en espectadores o voyeurs al contemplar el desarrollo de un acontecimiento misterioso y sorprendente. La investigadora relaciona esta tendencia con el énfasis que los médicos ilustrados ponen en la importancia que para el análisis de un fenómeno tiene la percepción, en particular, la percepción visual (Kennedy, 2010, p. 35), conforme al giro señalado en los párrafos anteriores. Asimismo, vincula el interés por lo espectacular con la predominancia de lo ocular en el discurso médico dieciochesco y opina que esta estrategia de representación de la enfermedad alentaba la curiosidad de los lectores.

Efectivamente, la obra de Ibáñez abunda en imágenes que ponen de manifiesto un intento de "espectacularización" de la enfermedad. Al comentar las consecuencias del brote de la epidemia en España, el autor advierte: "[p]aréceme que en vista de tan lamentable escena, se ofrecía motivo para desamparar el sitio" (p. 6). En otro pasaje, que se refiere a los achaques de las tercianas en la villa de Pastrana, relata:

Acometieron a los nobles y plebeyos, a ricos y pobres, a grandes y chicos, a fuertes y endebles. Las padecieron los hombres viejos y mozos, mujeres, doncellas, viudas y casadas, y para decirlo de una vez, fue comprehendido en esta plaga todo viviente nacional que le precisa estar rodeado del fluido aéreo contagiable y epidémico, de que ha habido muy pocos que se han escapado, o por mejor decir, nadie ha estado libre del maligno contacto que ha viciado el aire y demás mantenimientos que sustentan al hombre, que malquistan e indisponen para haber sufrido una escena de males tan crueles, como si fueran tiranos homicidas (p. 13-14).

Repetidas veces presenta el autor los sucesos de la epidemia como escenas protagonizadas, precisamente, por la fiebre. En el fragmento que aparece en la sección dedicada a la característica de los síntomas de las tercianas, observa:

Apenas calma este primer ímpetu accesional, cuando empieza a arrojar llamas la escena febril, quémase, y se abrasa el enfermo tercianario, pues no hay calor que iguale al acrecentarse la terciana, ni abundancia de agua que le apacigüe (p. 40).

La asociación de la fiebre con el fuego no es nada sorprendente; además, la imagen de un cuerpo consumido por el ardor de la fiebre es muy frecuente en los escritos médicos, incluyendo los textos dedicados a las calenturas intermitentes del siglo XVIII (cf. Rodón y Bell, 1787, p. 16; Nieto de Piña, 1787, p. 30; Hilario Cavaller, 1785 , p. 23). No obstante, al utilizar la fórmula "escena febril", Ibáñez otra vez insiste en la dimensión espectacular de la enfermedad. En el apartado dedicado al uso de la quina -según él, el único fármaco efectivo contra las tercianas- indica que al aplicar cantidades insuficientes de este medicamento, los médicos "representan una tragedia muy funesta" (p. 79). Parece entonces que las "escenas" de los avances de la enfermedad que no se curan con remedios adecuados componen una "tragedia", es decir, todo un espectáculo del desarrollo de la malaria. Por otro lado, 
el autor con mucha frecuencia introduce en sus narraciones otros espectadores de dicho proceso, por ejemplo, en uno de los casos clínicos que evoca, relata que "[e]n el preciso y perentorio término de veinte y cuatro horas de seguida a la aplicación de los dos parches de vejigatorios, a presencia y vista de todos los asistentes y concurrentes, se notó con admiración ceder en el todo la calentura" (p. 74-75). El espectáculo en el que se convierte la enfermedad en el tratado de Ibáñez es contemplado por un público que -junto al autor y al lector- sigue los sucesos de la epidemia.

El pensamiento médico de Ibáñez en la Topografia hipocrática... está expresado por medio de imágenes que dimanan de la manera en la que el autor entiende las causas, los progresos y las consecuencias de la epidemia de fiebres tercianas. La aplicación de estos recursos no constituye un intento de estetización de la enfermedad, sino que vehicula un deseo de objetivización del discurso médico sobre la malaria, siendo "la visualización [...] el medio par excellence de objetivación en la tradición biomédica occidental" (Ortega, 2010, p. 91). Paralelamente, al inscribirse en la poética de la representación orientada hacia la predominancia de la imagen sobre cualquier otro medio de expresar conocimientos científicos, el tratado de Ibáñez constituye una buena ilustración del crecimiento de la importancia de lo visual en la medicina del setecientos. 


\section{BIBLIOGRAFÍA}

Alegre Carvajal, E. (2019). El discurso médico-higienista ilustrado y su incidencia en Pastrana, una ciudad ducal del Renacimiento. In L. Sazatornil Ruiz \& A. Urquízar Herrera (Eds.), Arte, ciudad y culturas nobiliarias en España (siglos XV-XIX) (pp. 252-265). Madrid: Consejo Superior de Investigaciones Científicas.

Biblia de Jerusalén (1975). Bilbao: Desclée de Brouwer.

Carmona, J. I. (2005). Enfermedad y sociedad en los primeros tiempos modernos. Sevilla: Universidad de Sevilla.

Casco Solís, J. (2001). Las topografías médicas: revisión y cronología. Asclepio, 53 (1), 213-244. DOI: 10.3989/asclepio.2001.v53.i1.178

Cera Brea, M. (2013). La memoria visual de la arquitectura española en los grabados de la Edad Moderna. Anales de Historia del Arte, 23, 37-50. DOI: 10.5209/rev_ANHA.2013.v23.41901

García Varas, A. (2017). Investigación actual en imágenes. Un análisis comparativo del debate internacional sobre la imagen. El Ornitorrinco Tachado. Revista de artes visuales, 6, 23-39. URL: https://ornitorrincotachado.uaemex.mx/article/view/9276

Giménez-Font, P. (2008). La epidemia de malaria de 1783-1786: notas sobre la influencia de anomalías climáticas y cambios de usos del suelo en la salud humana. Investigaciones Geográficas, 46, 141-157. DOI: 10.14198/INGEO2008.46.08

Granjel, L. (1979). La medicina española del siglo XVIII. Salamanca: Ediciones Universidad de Salamanca.

Hilario Cavaller, F. (1785). Fransisco Hilario Cavaller, escrivano del Rey Nuestro Señor, público $y$ vecino... de Valencia, uno de los ayudantes de la Escrivania Mayor de Ayuntamiento... encargado del ramo de Sanidad de Mar y Tierra. URL: https://bivaldi.gva.es/es/catalogo imagenes/grupo.do?path=1005261

Ibáñez, F. (1795). Topografia hipocrática o descripción de la epidemia de calenturas tercianas intermitentes malignas, continuo-remitentes, perniciosas complicadas. Madrid: Imprenta de Ramón Ruiz. URL: Biblioteca Digital Hispánica database.

Kennedy, M. (2010). Revising the Clinic. Vision and Representation in Victorian Medical Narrative and the Novel. Columbus: The Ohio State University Press.

Malaria (2014). In Diccionario de la Real Academia Española. URL: https://dle.rae.es/ma laria? $\mathrm{m}=$ form

Mitchell, W. J. T. (2009). Vier Grundbegriffe der Bildwissenschaft. In K. Sachs-Hombach (Ed.), Anthropologische und kulturelle Grundlagen des Visualistic Turn (pp. 319-327). Frankfurt am Mein: Suhrkamp.

Nieto de Piña, C. (1787). Memoria de las enfermedades experimentadas en la ciudad de Sevilla en el año de 1786. Sevilla: Imprenta de la Viuda de Vázquez, Hidalgo, y Compañía. URL: Biblioteca Digital Hispánica database.

Ortega, F. (2010). El cuerpo incierto. Corporeidad, tecnologías médicas y cultura contemporánea. Madrid: Consejo Superior de Investigaciones Científicas.

Paludismo (2014). In Diccionario de la Real Academia Española. URL: https://dle.rae.es/ paludismo\#BlZUboo

Rodón y Bell, M. (1787). Relación de las epidemias que han afligido a la ciudad de Cartagena. Cartagena: Imprenta de D. Pedro Ximénez. URL: Biblioteca Digital de Murcia database.

Stafford, B. (1997). Body Criticism. Imaging the Unseen in Enlightenment Art and Medicine. Cambridge, Massachusetts \& London: Massachusetts Institute of Technology.

Vega, J. (2011). Monumentalizar la ciudad y registrarla, una contribución moderna al conocimiento. Revista de Dialectología y Tradiciones Populares, 66 (1), 229-240. DOI: 10.3989/rdtp.2011.09 